Article

\title{
Decision Support to Sustainable Parking Management-Investment Planning through Parking Fines to Improve Pedestrian Flows
}

\author{
Majda Ivić *®D, Jelena Kilić(D, Katarina Rogulj and Nikša Jajac \\ Faculty of Civil Engineering, Architecture and Geodesy, University of Split, Matice hrvatske 15, \\ 21000 Split, Croatia; jkilic@gradst.hr (J.K.); krogulj@gradst.hr (K.R.); njajac@gradst.hr (N.J.) \\ * Correspondence: mivic@gradst.hr
}

Received: 9 October 2020; Accepted: 11 November 2020; Published: 14 November 2020

check for updates

\begin{abstract}
With the urbanization and expansion of cities, which have taken place over recent decades, new demands and problems are emerging, among which is the problem of inadequate transport infrastructure. The number of motor vehicles is growing, while transport infrastructure is not following that growth fast enough. One of the problems that arises is the insufficient number of garages and parking lots, causing an increase in illegal parking on sidewalks, which impedes and endangers pedestrian traffic. This paper proposes a new decision support concept (DSC) for the management of illegally parked cars in urban centers, which offers a method that can contribute to solving this problem and improving the flow of pedestrians on city roads. Due to its complexity, the problem addressed in this research is recognized as a multicriteria one and therefore the proposed model is based on the use of multicriteria analysis methods-more precisely, the Preference Ranking Organization Method for Enrichment Evaluation-PROMETHEE, and the analytic hierarchy process-AHP. The proposed DSC is validated in the city of Split (Croatia), more precisely in the neighborhood of Sucidar, which shows that this methodology is applicable and effective for finding not a temporary but a permanent solution to the problem described.
\end{abstract}

Keywords: decision support concept; illegal parking; parking violation; multicriteria methods; PROMETHEE; GIS

\section{Introduction}

Expansive urbanization, that has taken place over the last few decades, has led to the rapid expansion of cities, and consequently to new types of problems. Due to changes in living conditions, the need for mobility and the aspirations of people for better living conditions, the number of motor vehicles is continually increasing, while on the other hand, the development of traffic infrastructure often does not follow this fast enough. Problems arise when existing infrastructure, designed for much lower traffic, cannot accommodate such an increase, which then causes issues like traffic congestion, in both fluid and stationary traffic. An essential component in the transportation system is stationary traffic, which has lately been increasingly challenging for traffic experts since, with their expansion, cities all around the world have a lot of issues with the lack of parking places. According to [1], passenger cars spend about $90 \%$ of the time being at a standstill, which makes stationary traffic substantial for the functioning of the transportation system and it becomes very important to devote time to its planning and designing.

Nowadays, quality of life in cities is very much dependent on the quality of transportation infrastructure and the sustainability of the urban transport system. In order to provide quality and a sustainable system, a transport demand management strategy is often applied, with the purpose 
of changing the modal distribution of motorized and non-motorized travel and reducing excessive use of personal vehicles. To accomplish this, it is also important to include stationary traffic in the strategies, or to be more precise, the parking policy should be a function of the city's overall traffic policy [2]. Problems occur at a time when demand for parking overgrows the parking offered, which leads to the growing issue of parking violation within city centers, resulting in new problems such as disruption of pedestrian traffic. A large number of vehicles that are illegally parked on the sidewalk, even where parking spaces are not provided, often do not leave enough space for pedestrian passage. Such vehicles also impede traffic in other ways and can cause traffic congestion and increase the risk of road accidents.

Dealing with the problem of parking violation and illegally parked cars is quite complex with no universal and simple solution, and it depends on the local circumstances. The complexity arises from the fact that it involves various participants whose different opinions, needs and capabilities need to be taken into account. For example, citizens demand safe and passable pedestrian paths and are in need of new parking lots or garages where they can leave their vehicles in order not to further impede traffic, traffic experts need to meet the maximum quality of stationary traffic and parking infrastructure with limited free space and city government experts have to balance between a restricted budget and improving the quality of life in the city they manage. Due to the different attitudes of stakeholders towards the solution of the analyzed problem, it is necessary to find the best possible outcome that includes the opinions of all participants, that is, a compromise solution.

This paper will focus on the research problem of a large number of illegally parked cars on sidewalks in urban centers and the method that can contribute to solving this problem and improving pedestrian flows along urban roads. The aim of the paper is to model a new decision support concept (DSC) that would help in the management and planning of transportation infrastructure by improving decision-making processes. Given the complexity of the problem presented, the large number of different data and the large number of participants associated with it, as well as different requirements that need to be met, the proposed model is based on the use of multicriteria analysis methods, more precisely the Preference Ranking Organization Method for Enrichment Evaluation-PROMETHEE [3], and the analytic hierarchy process-AHP [4].

The proposed DSC is validated in the city of Split (in Croatia) or more precisely in its neighborhood Sućidar. The city of Split has significant problems with the lack of parking places, and this is partly due to the fact that some of its neighborhoods were not built according to the city plans. The problem becomes more apparent during the summer months when, due to tourism, the number of people in the city grows rapidly, for which the transportation and other infrastructures are not adequately prepared. The data were collected in the period from 2016 to 2018, but in order to validate the proposed DSC, the representative sample of a one-day time period was used. The smartphone application "GIS Cloud Mobile Data Collection", which provides real-time data collection, visualization and monitoring, was used for the data collection. GIS Cloud offers a complete location-based solution for different tasks in fields such as roadworks, tree inventory and inspection, retail, smart cities, utilities such as water and pipeline management, natural resources, public city maps and similar fields [5].

\section{Literature Review}

Since 2000, the use of multicriteria analysis in decision making in transport infrastructure projects has significantly increased. It is mainly used in the infrastructure planning phase and examples of its use can be found in various countries around the world [6].

Deluka-Tibljaš et al. [6] provided a review of multicriteria analysis methods application in decision making for the planning, designing, maintenance and rehabilitation of transport infrastructure in urban areas. Jajac et al. [7] proposed a DSC for the management of urban transport projects, more precisely the planning phase of urban road infrastructure projects, based on multicriteria methods and artificial neural networks. Jajac et al. [8] proposed a generic decision support system (DSS) for urban infrastructure management, with three management levels (operative, tactical and strategic), 
which is applied for solving site selection and the sub-project ranking problem and for defining an investment strategy, in a big parking garages project. For that purpose, two multicriteria methods, AHP and PROMETHHE, were used, as well as 0-1 programming. Similar studies dealing with garage parking facility location selection using the multicriteria approaches AHP and/or PROMETHEE can be found in [9-11].

Jelokhani-Niaraki and Malczewski [12] presented a multicriteria spatial decision support system (MC-SDSS) - a web platform that integrates GIS and multicriteria decision analysis to address the problem of parking site selection in Tehran. The proposed system consists of two elements: deliberate and analytic. The analytic part is based on two methods: an ordered weighted averaging (OWA)-based approach, for generating individual solutions, and a Borda-based method for combining the individual preferences to obtain a consensus solution. Using the map, which makes up a deliberate part of the system, provides decision makers with information about the spatial distribution of the geographic entities, and offers them a map-centered argumentation tool in order to find the best compromise solution.

Jajac et al. [13] also presented a decision support concept for managing the maintenance of city parking facilities. The DSC, which combines AHP and PROMETHEE multicriteria methods to rank the priorities and define the implementation phases of maintenance, is validated in the city of Split.

Among the studies dealing with problems related to parking violation and illegal parking, there are many research works that analyzed those issues and tried to address them in different ways. For example, Davtyan [14] examined the use of on-street parking meters in downtown of Stamford in order to find out about the parking behavior and possible violations, and to estimate if meters were profitable for the city. Applying the decision tree showed that it is worthy for a costumer to pay the meter, and that increased enforcement and penalties reduce illegal parking. The research also showed that for the city, it is profitable to have meters in the area. Khantasak et al. [15] presented a parking violation detection system based on video processing, in order to address the problem of parking violation in Hat Yai city in Thailand, by detecting the violation and informing the police in time. The proposed system processes the videos and detects if there were vehicles in the parking area. Moreover, the system can also identify moving vehicles using the background subtraction method. Kim et al. [16] proposed a method to automate the regulation of illegal parking by obtaining photos with a camera mounted on enforcement vehicles and using computer vision technology. Illegal parking is detected by the comparison of the lanes, extracted using the Canny operator and Hough transformation, and the vehicle's shadow, which is detected by processing the image using fuzzy binarization. Dinh and Kim [17] highlighted the problem of parking violation management in smart cities and developed a location-centric, cloud-based parking violation management system. Data obtained by parking sensors are gathered and processed on the cloud, while the violation information is distributed to parking officers based on their location. Evaluation of the system, which was performed on the real sensor dataset from the City of Melbourne, showed that the proposed system can improve the efficiency of parking officers, which may result in a reduction in the number of violations and violation periods.

To the best of our knowledge, there is no available research dealing with the problem of illegal parking on sidewalks by applying multicriteria methods in order to improve decision-making processes. The justification of multicriterial analysis is based on the possibility to see through it all relevant aspects of this problem and to involve all relevant stakeholders in the solution who will give their view of the problem. The specific way of applying multicriterial analysis is presented here, and it is highlighted that previous research on this issue has not included the application of multicriterial analysis in this integral and inclusive way. Moreover, most of the studies were focused on improving the parking management system by improving the methods of detecting parking violations in order to reduce them by charging fines, but no papers have been found describing research on the possibility of modeling a single decision-making process that will take into account all of the above. Such a process with clearly defined steps, necessary adequate data and engaged adequate methods (for each of the steps) for processing these data based on the logic of multicriterial analysis is the result of the research presented 
in this paper. This research proposes a unique way to solve the problem of illegal parking by charging parking fines of relatively small amounts, thus raising funds for the construction of parking lots and garages to provide more legal parking lots, where improperly parked cars are ranked according to how much they endanger traffic.

\section{Materials and Methods}

\subsection{Analytic Hierarchy Process}

The analytic hierarchy process (AHP), developed by Saaty in the 1970s, is one of the most widely used multicriteria decision-making tools that provides a hierarchical representation of a system and gives a relative importance of alternative courses of action. AHP divides a complex decision-making problem in different levels of the hierarchy, while the components of each level are compared relative to each other using a pairwise comparison. Integration across the levels of hierarchy is achieved by relating components of a level to an adjacent upper level. Due to the flexibility in constructing the hierarchy and suitability for group decision making, AHP has found wide application in many areas of science and practice [18]. The purpose of the AHP method in practice is assigning weights to tested elements. Weights are used to prioritize the elements in order to define the key elements or to establish the key measurements for business performance and thus make more accurate business decisions [19].

The procedure of applying the AHP method can be divided in four basic steps [4]:

- Modeling a hierarchical structure which consists objectives, a variety of criteria and alternatives. At the top of the hierarchy is the main goal of decision making, intermediate levels consist of the objectives that support the main goal and below them are criteria that influence the decision. The lowest level is usually a list of alternatives.

- Defining a comparison matrix of elements of each hierarchy level. In order to define matrices, individual comparisons are translated into scale values and the preferences of decision makers are expressed through Saaty's nine-point scale.

- Priority determination. A matrix of relative rankings for each level of the hierarchy is generated through the pairwise comparison, while the number of the matrix depends on the number of elements in each level. After defining the matrices, for each matrix, the vector of relative weight and the maximum eigenvalue $\left(\lambda_{\max }\right)$ are calculated.

- Evaluating the validity of comparisons by the consistency ratio (CR). In order to define the consistency ratio, it is necessary to calculate the consistency index $\mathrm{CI}$, which is, for an $n \times n$ matrix, defined as $\mathrm{CI}=\left(\lambda_{\max }-n\right) /(n-1)$. The consistency ratio is then calculated as $\mathrm{CR}=\mathrm{CI} / \mathrm{RI}$, where the $\mathrm{RI}$ value is the random consistency index. The $C R$ value is acceptable if it is equal to or less than a certain value that depends on the size of the matrix ( 0.1 for matrices $n \geq 5)$. This proves that the evaluation within the matrix is allowable and close to ideal values.

\subsection{Preference Ranking Organization Method for Enrichment Evaluation}

The PROMETHEE methodology, developed by J. P. Brans and B. Mareschal in 1983, is well accepted and widely used among decision makers because it is comprehensive and provides a presentation of the results by using simple ranking [3]. The methodology was developed to aid decision making in multicriteria problems and enables the comparison and ranking of different alternatives that are simultaneously evaluated based on multiple quantitative or qualitative criteria. The PROMETHEE family includes six outranking methods $[3,20]$, but for this research, PROMETHEE II has been selected as the most appropriate one.

An input for the PROMETHEE method is matrix $A$, composed of a set of potential alternatives (actions). Each element $a$ of matrix $A$ has its $f(a)$, which is the evaluation of one criterion, and each evaluation fi(ai) must be a real number.

The implementation of PROMETHEE requires two additional types of information: the weights and the preference function. PROMETHEE assumes that the decision maker is able to weigh the criteria 
and does not provide specific guidelines for determining the weights so they can be determined by various method [21].

Proposed by $[3,20]$, there are six types of preference functions: Usual criterion, U-shape criterion, V-shape criterion, Level criterion, Linear criterion and Gaussian criterion. The functions have values between 0 and 1 , which express the preference of the decision maker.

If the values are closer to 0 , this means the greater the indifference of the decision maker. The closer the values are to 1 , the greater the preference, so if the decision maker has a strict advantage, the preference function will be 1 . The use of a particular type of function depends on the characteristics of the criteria [22]. For each criterion, the analyst and the decision maker choose one of the six functions in common agreement, with regard to their knowledge about the intensity and direction of preference.

The PROMETHEE I method provides a partial ranking of the alternatives, with the following dominance flows, for the positive outranking flow $\phi^{+}(a)[3]$ :

$$
\phi^{+}(a)=\frac{1}{n-1} \sum_{x \in \mathrm{A}} \prod(a, x)
$$

and the negative outranking flow $\phi^{-}(a)[3]$ :

$$
\phi^{-}(a)=\frac{1}{n-1} \sum_{x \in \mathrm{A}} \prod(x, a),
$$

where $a$ and $x$ represent actions or alternatives from the set of alternatives A (during the pairwise comparison of action $a$ with all other $n-1$ actions), $n$ represents the number of alternatives and $\Pi$ is the preference index, which is defined for each pair of actions [3]:

$$
\prod(a, x)=\frac{\sum_{j=1}^{n} w_{j} P_{j}(a, x)}{\sum_{j=1}^{n} w_{j}},
$$

where $w_{j}$ is a weight of criterion $\mathrm{j}$ and $P_{j}(a, x)$ represents the preference of $a$ over $x$ for a given preference function of criterion $j$. Given that $\sum_{j=1}^{n} w_{j}=1$, the equation can be written as

$$
\prod(a, x)=\sum_{j=1}^{n} w_{j} P_{j}(a, x),
$$

Now, the PROMETHEE II method, which ranks the actions according to a complete ranking for the calculated net flow, can be applied and a net outranking flow can be obtained [3]:

$$
\phi(a)=\phi^{+}(a)-\phi^{-}(a) .
$$

\subsection{Decision Support Concept to Management of Illegal Parking}

The architecture of the proposed decision support concept is based on the previous experience of the authors in applying presented and similar methodologies in addressing different kinds of problems. The proposed generic DSC for the management of illegal parking is shown in Figure 1.

Application of the concept begins with defining and describing the research problem, which include identifying and organizing the relevant stakeholders and their representatives. The selected stakeholders can be divided into three groups: citizens, traffic experts and city government experts. Each of these groups consists of several members who are considered to be relevant representatives of the stakeholder group, and who should convey the opinions and represent the interests of the group to which they belong. Given that the addressed issue is a multicriterial problem, the participation of representatives of different stakeholder groups increases transparency and helps to reach a consensus 
solution that will, as far as possible, cover the opinions and requests of all groups concerned by the problem.

Defining a research problem also involves analyzing existing planning and regulatory documentation conducted by traffic experts and members of the local government. An analysis of the strategies and plans, as well as the laws and regulations of the Republic of Croatia, related to the regulation of parking violations and pedestrian flows along the roads, is performed in order to better understand the proposed problem and the current situation within the research area.

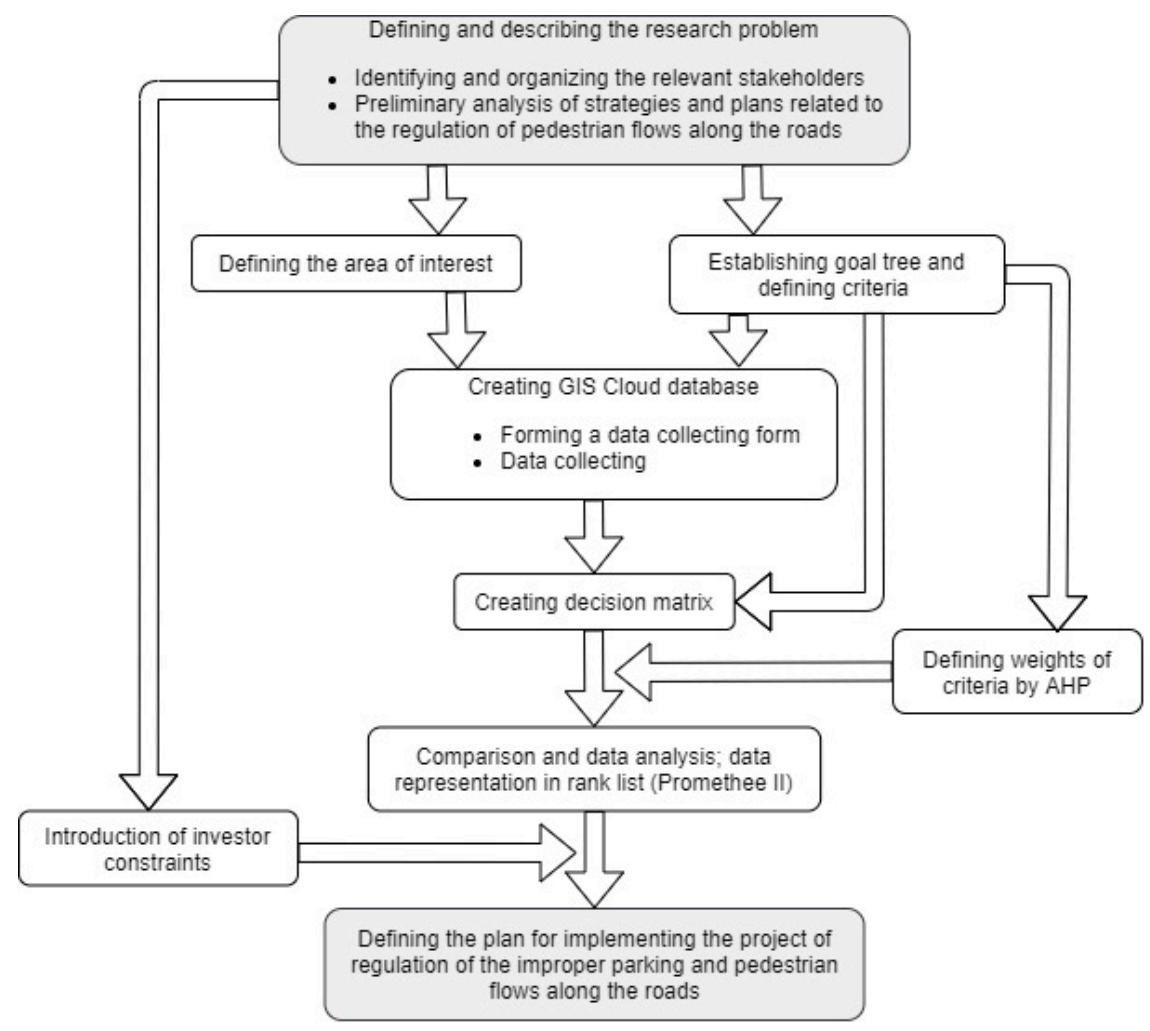

Figure 1. Concept for the management of illegal parking.

The next step consists of two activities that are simultaneously conducted by the engaged stakeholder representatives. The first activity includes spatial analysis, site selection and defining the boundaries of the area where the proposed concept will be applied. The definition of the area of interest is based on the analysis of the existing planning documentation, strategies and regulations that was performed in the previous step by the chosen experts involved. The selection of the study area took into account the opinion and needs of the citizens, expressed by the representatives of the stakeholder group, as well as the population density and quantity in particular areas of the city.

The second of the two activities, in which all the stakeholders are also involved, is designing the goal hierarchy structure (GHS) in the form of a goal tree, consisting of the main goal, its objectives and the criteria. The establishment of a GHS provides a higher quality of the objective generation process, as it gives a good insight into the relationship between the main goals and the objectives, and between objectives and their criteria [23]. These two activities take place in parallel, with the same stakeholders involved who simultaneously study and define the basic determinants of the area of interest as well as the goals or criteria that arise from them. Namely, sometimes the desired goal is crystallized from the analysis of the area of interest, and often the established evaluation criterion indicates the relevant characteristics of the area of interest. So, these are two processes that complement each other.

The structure of the goal tree is established on the basis of face-to-face discussions and group decision making using the brainstorming technique on the presented problem. All stakeholders participate in formulating and defining the goals, objectives and criteria, which are finally selected 
by a mutual agreement. A particular stakeholder group is put in charge when it is needed to define the goals and criteria related to its area of expertise, while other stakeholder groups participate in the decision-making process with suggestions and advice. However, it must be emphasized that a certain criterion can only be included in the decision tree when all representatives of stakeholder groups have agreed and approved it.

Definition of the GHS starts with the formulation of the main goal, located at the top of the hierarchy, which is the beginning of the goal tree. The main goal is divided into several supporting subgoals or objectives which need to be fulfilled so the main goal can be reached. Objectives also have their supporting objectives, and it goes on like that until the level where they can no longer be divided or there is no need for their further division. At that point when objectives became measurable, they can be considered and adopted as criteria. When all the subdivisions of objectives into sub-objectives are completed, the goal tree is established [24].

GHS provides insight into the relationships between objectives considering the levels of the hierarchy, however it does not provide information on the relative importance of objectives at the same level. It is especially important to determine the relative relationships of objectives in the last hierarchical level since they will be used as criteria in the process of evaluating and ranking alternatives [9]. Relative relationships or the importance of criteria are defined by their weights, while alternatives in this case represent illegally parked cars.

The weights of the criteria are determined by each stakeholder group, given the importance that each criterion represents for them, using the AHP method. Each such set, or a combination of criteria and their respective weights, represents a different strategy also known as a scenario. In order to ensure that the requirements and desires of all stakeholder groups are equally respected in the decision-making process, as the final weights to be used in the evaluation and ranking of alternatives, compromise weights are determined by the arithmetic mean.

The following step is creating a GIS Cloud database and it consists of two activities: forming a data collecting form and data collecting. Establishing the database is based on a previously defined goal tree, which means that data will be obtained according to the criteria adopted. In order to ensure uniform data collecting, it is necessary to create a form that will be used in a mobile GIS application to collect the necessary metadata for each individual alternative, on the basis of which criteria values will be generated.

The next step is forming a decision matrix that includes the evaluation of all alternatives (illegally parked vehicles) according to all criteria, using the collected data and previously defined assessment techniques, and the selected preference functions. When defining preference functions for each criterion, attention should be paid to determining whether the problem is minimal or maximum, as well as selecting the appropriate shape of the preference function [25].

After obtaining all of the necessary input data consisting of criteria weights, preference functions and, finally, the decision matrix, the next step involves analysis and evaluation of data using the PROMETHEE II method. The method is applied to the compromise scenario, whose criteria weights are defined as the average of the weights of criteria over all scenarios, in order to obtain the priority rank list of given actions. In the last steps, after obtaining a full ranking of all the alternatives, it is necessary to introduce investor constraints, based on which the project implementation plan can finally be elaborated.

\section{Application of the Proposed Concept}

\subsection{Definition of the Research Problem and the Area of Interest}

There is an exceptional lack of parking spaces in the city of Split caused by a large increase in the number of vehicles and the fact that parts of the city were not built according to the city plans, but instead consist of spontaneous, disorganized housing, often illegally built. In such parts of the city, improper parking on the sidewalk is a common practice and is often tolerated if there is plenty of space 
for pedestrians to pass. However, it often happens that parked vehicles occupy the entire, or almost the entire, sidewalk and there is no minimum space for pedestrians to pass. Therefore, the main idea of this research is the sustainability of pedestrian flow quality, which is supported by the construction of new parking facilities, which will give residents the opportunity to park their cars in legal places and to reduce the pressure of parking on sidewalks.

The problem of illegally parked cars, that obstruct pedestrian traffic along the streets, has been recognized as a multicriterial problem as it does not have a simple and unique solution. In addition to the multitude of stakeholders whose opinions and requests need to be taken into account when approaching this issue, finding a solution is also affected by a range of criteria and various constraints and limitations. Therefore, in order to successfully solve this complex problem, it was necessary to develop the presented specific decision-making process, whose implementation will be provided below.

The implementation of the process began with a more detailed exploration and description of the problem, and one of the key parts of that first step is the identification and gathering of relevant stakeholders. For the purpose of this research, three stakeholder groups were gathered-citizens, traffic experts and city government experts, and three representatives were selected for each group. The group representatives were selected based on their expertise and experience in the field of research, as well as their recognition by the group members.

After grouping the stakeholders, based on a thorough study of the existing documentation, acts and regulations, the area of interest for conducting the research was selected, that is, the city district in the town of Split (Croatia), which seemed appropriate to test the proposed concept (Figure 2). After consultation and brief consideration, it was decided that this would be the city district of Sućidar bounded by the following streets: from north to east and south by Velebitska Street from the junction with Bruno Bušić Street to the intersection with Vukovarska Street; from west by Bruno Bušić Street from the crossroads with Vukovarska Street to the crossing with Velebitska Street; and from south by Vukovarska Street from the intersection with Street Bruno Bušic to the intersection with Velebitska Street.

Due to the increasing number of vehicles that follows the growth of the urban population, a lot of cities worldwide are experiencing problems with transport infrastructure, of which parking facilities are a part of, and the city of Split is no exception. Sućidar is a neighborhood in the city of Split, located in the eastern part of the city, and can be considered as one of the parts that have major problems with the lack of parking space. This is partly due to the population density since, according to the latest urban development plan [26], there are approximately 12,000 inhabitants in about 43 ha of residential area. Another problem lies in the fact that some parts of this neighborhood were not built according to city plans and there is not enough space left for parking.
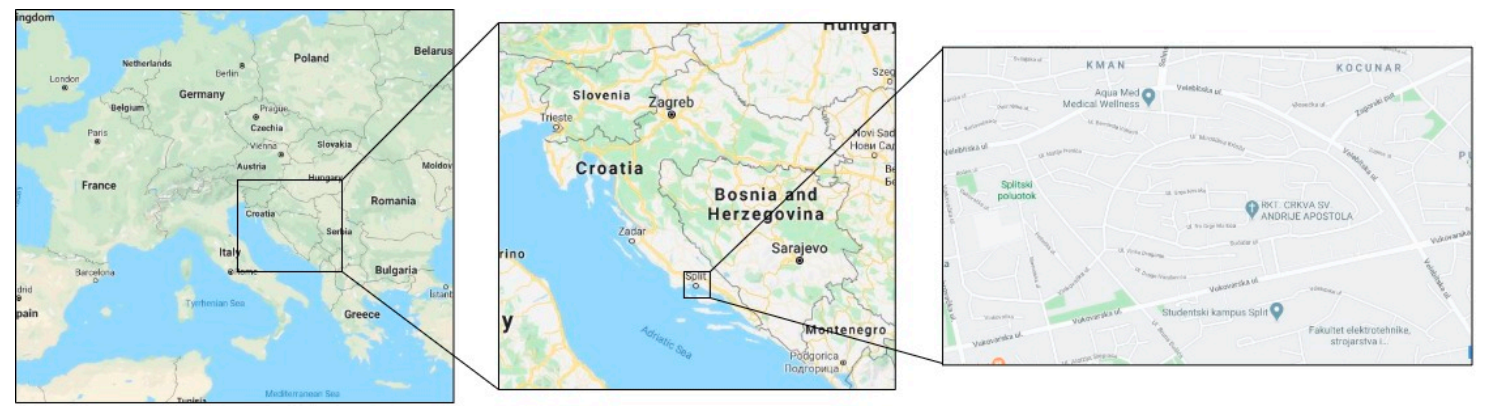

Figure 2. Neighborhood of Sućidar in the city of Split, Republic of Croatia.

In the area of Sućidar, there are zones of organized housing and zones of spontaneous, disorganized housing, where a large proportion are illegally constructed facilities. In the areas of organized housing, multi-story buildings (up to 17 floors) are predominant, while in the spontaneously built zones, there are mostly family buildings. In such zones of disorganized housing, the problem is with the transport 
network and other infrastructures which are often uncompleted, and with buildings and auxiliary buildings that generally extend to the very edge of the public road or to the boundary of the parcel [26].

The city district of Sućidar lacks playgrounds, green areas and parks, and the problem with stationary traffic is particularly pronounced. For example, there are only 285 parking spaces in one of the areas where parking facilities are provided (parking lot south of the kindergarten and parking lot between Krležina and Velebitska Streets), while there are 1385 apartments built in that area. In such areas, due to the significant lack of parking spaces, streets are usually used for parking, which impedes the traffic [26].

\subsection{Definition of the Goal Hierarchy Structure and Criteria Weights}

Parallel with defining the area of interest, the activity of designing the GHS was conducted. In order to obtain the most objective and optimal structure, all stakeholders participated in defining the structure, as well as in generating individual goals through the brainstorming sessions. Brainstorming sessions were repeated through several iterations until a consensus solution was reached. It should be noted that the proposed structure can be modified and adapted to the characteristics of the area in which it is applied.

The GHS used in validating the concept proposed for solving the problem of illegal parking in the neighborhood of Sućidar in Split is shown in Figure 3. The figure shows the relationships between the goals and criteria, while their hierarchical levels, labels and names can be seen in Table 1. The main goal is marked with MG, while objectives have labels MO1, MO2 and MO3. The criteria are marked with $\mathrm{C} i$, where $\mathrm{i}$ is the number of criteria, which is determined by interval $\mathrm{i}=1,2, \ldots, 10$.

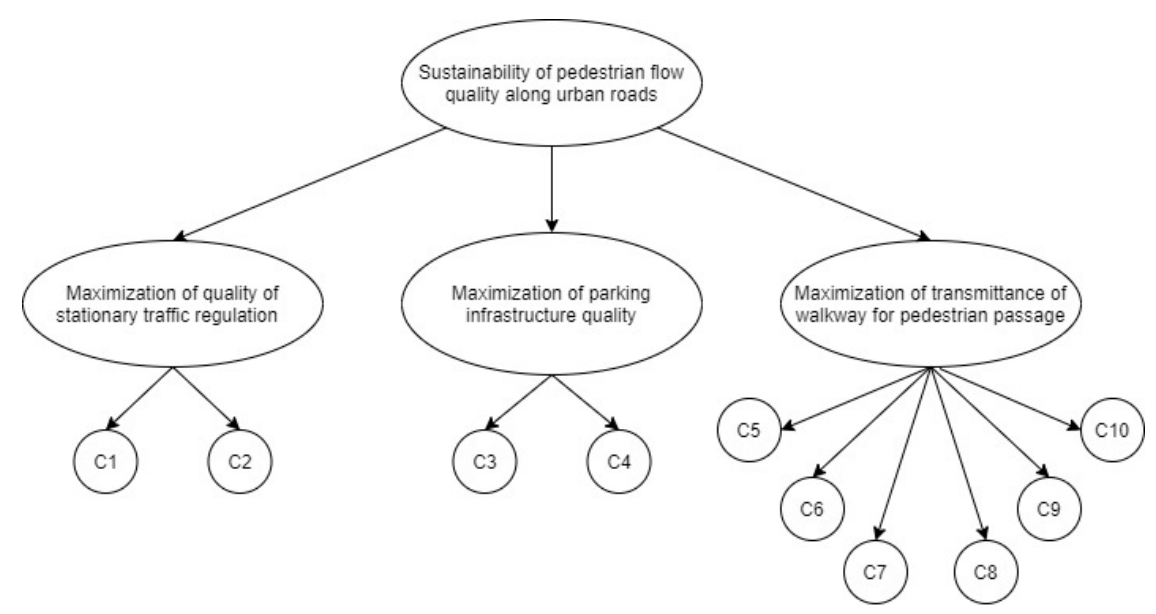

Figure 3. Goal hierarchy structure (GHS).

Table 1. Hierarchy level, label and name of each element of the GHS.

\begin{tabular}{ccc}
\hline Level & Label & Name \\
\hline 1 & MG & Sustainability of pedestrian flow quality along urban roads \\
2 & Maximization of quality of stationary traffic regulation \\
2 & MO2 & Maximization of parking infrastructure quality \\
2 & MO3 & Maximization of transmittance of walkway for pedestrian passage \\
3 & C1 & Parking restriction \\
3 & C2 & Parking charge \\
3 & C3 & Car parked on the walkway-whole or half \\
3 & C4 & Type of parking \\
3 & C5 & Walkway width \\
3 & C6 & Walkway cover \\
3 & C7 & Road type \\
3 & C8 & Parking direction \\
3 & C9 & Roadway width \\
3 & C10 & Space for pedestrian passage on the walkway \\
\hline
\end{tabular}


Defining the GHS began with the main goal-“"sustainability of pedestrian flow quality along urban roads", which was then divided into three supporting objectives that need to be fulfilled in order to accomplish it. The three objectives are: "maximization of quality of stationary traffic regulation", "maximization of parking infrastructure quality" and "maximization of transmittance of walkway for pedestrian passage". As stated above, all stakeholders were involved in defining the GHS, so these three goals are a product of their collaboration. Each group defined goals according to their expertise, their knowledge and practical experience in their field, and then the other stakeholder groups made their suggestions. After the discussions, a common agreement was reached, and ultimately these three goals were included in the goal tree.

Each of these three objectives is further divided into several supporting objectives. More specifically, $\mathrm{MO} 1$ and MO2 are divided into two sub-objectives, while MO3 is divided into six sub-objectives. These ten sub-objectives represent the criteria for evaluating the alternatives and were adopted as criteria when it was decided by consensus of all stakeholders involved that they were measurable and could not be further divided. A few other criteria were discussed at the beginning of the debate, but they were rejected because they could not be used to evaluate alternatives in this specific case or, to some extent, overlapped with some other criteria.

Table 2 for all criteria shows the criterion label, its brief description and techniques used for evaluation, as well as how the preference for that criterion was formed. Four criteria were determined to be minimized, which means that alternatives with lower values, obtained by the evaluation techniques presented, will be ranked higher. The remaining six criteria were determined to be maximized, which means that the higher-value alternatives, obtained by the evaluation techniques presented, will be ranked higher.

Regarding the preference functions, the Usual function prevailed and was used with seven criteria, while the V-shape function was used for the remaining three criteria. The preference function was used to translate the difference between two alternatives for a given criterion, from the criterion scale to a normalized degree of preference (0-1). The Usual preference function is the simplest one and it has no thresholds. By the Usual function, two actions with equal values (difference $=0$ ) are indifferent (preference degree $=0$ ), while two actions with different values (difference $>0$ ) generate a full preference (preference degree $=1$ ), regardless of the size of the difference. V-shape preference functions are slightly different and there is a notion of a preferential threshold $(\mathrm{P})$ and variable preference degree. According to the V-shape preference function, two actions with equal values (difference $=0$ ) are indifferent (preference degree $=0$ ) and two actions with quite different values (difference $>P$ ) generate a full preference (preference degree $=1$ ), while two actions with smaller different values (difference $\leq P$ ) generate a preference degree proportional to the difference (preference degree $=$ difference/P) $[27]$.

Table 2. Criteria descriptions and preference functions.

\begin{tabular}{|c|c|c|c|}
\hline Criteria Label & Short Description of Criteria and Technique for Evaluation Solutions & \multicolumn{2}{|c|}{ Preference } \\
\hline $\mathrm{C} 1$ & $\begin{array}{l}\text { It is determined whether there is a parking ban or not-expressed as follows: if } \\
\text { there is a parking ban-1; if not- } 0\end{array}$ & $\max$ & Usual \\
\hline $\mathrm{C} 2$ & $\begin{array}{l}\text { It is determined whether there is a parking fee or not-expressed as follows: if } \\
\text { there is a parking fee- } 1 \text {; if not }-0\end{array}$ & $\max$ & Usual \\
\hline $\mathrm{C} 3$ & $\begin{array}{l}\text { It is determined whether the whole car is parked on the walkway or } \\
\text { not-expressed as follows: if the whole car is parked on the walkway-1; if } \\
\text { there is only half of the car parked on the walkway-0 }\end{array}$ & $\max$ & Usual \\
\hline $\mathrm{C} 4$ & $\begin{array}{l}\text { Expressed as follows: if the car is parked longitudinally-1; if the car is parked } \\
\text { vertically - } 4 \text {; if the car is parked diagonally-3 }\end{array}$ & $\max$ & V-shape \\
\hline C5 & Expressed in $\mathrm{m}$ & $\min$ & V-shape \\
\hline C6 & $\begin{array}{l}\text { It is determined whether there is a land cover on the walkway or } \\
\text { not-expressed as follows: if there is a cover-1; if not- } 0\end{array}$ & $\min$ & Usual \\
\hline $\mathrm{C} 7$ & Expressed as follows: if it is a two-way road- 1 ; if it is a one-way road-0 & $\max$ & Usual \\
\hline
\end{tabular}


The establishment of the GHS defines relative relationships between goals with respect to the hierarchy levels, however, in order to determine the relative importance of objects of the same level, it is necessary to determine their weights. Given that this is especially important for objectives at the last hierarchical level since alternatives will be ranked according to them, each stakeholder group determined the weights of the criteria separately using the AHP method [9]. The purpose of this method is defining the importance of the objectives/criteria of the lower level in the achievement of an objective of the higher level [28].

By adding weights to each criterion, three different scenarios were created: Scenario 1 corresponding to the stakeholder group citizens, Scenario 2 corresponding to the stakeholder group traffic experts and Scenario 3 corresponding to the stakeholder group city government. Further, the consistency ratio was determined, $\mathrm{CR}<0.1$, and for each scenario, criteria weights satisfied this condition. In order for all stakeholders to be involved in the decision-making process, Scenario 4, or a compromise solution, was created, where the weight of each criterion was determined as the arithmetic mean of the weights of that criterion over the first three scenarios. Scenario 4 was used to compare and rank the 462 alternatives. The weights of each criterion in the four defined scenarios are shown in Table 3.

According to the compromise solution, C3 (which defines whether the vehicle is parked on the walkway in whole or half) and C4 (which defines whether the vehicle is parked longitudinally, diagonally or vertically) proved to be the most important criteria or the criteria with the highest weights. This was to be expected given the problem that this research was trying to address and the fact that these two criteria describe the way the vehicle is parked on the sidewalk has a direct impact on reducing passability and impeding pedestrian traffic. The criteria with the lowest weights are criterion C7, which defines whether the road is two-way or one-way, and criterion C9, which expresses the width of the road, and which together refer more to the road than to vehicles illegally parked on the sidewalk.

Table 3. Criteria weights for the four scenarios.

\begin{tabular}{cccccc}
\hline & \multicolumn{5}{c}{ Criteria Weights } \\
\cline { 2 - 6 } Criteria Label & $\begin{array}{c}\text { Scenario 1 } \\
\text { (CITIZENS) }\end{array}$ & $\begin{array}{c}\text { Scenario 2 } \\
\text { (Traffic Experts) }\end{array}$ & $\begin{array}{c}\text { Scenario 3 } \\
\text { (City Government } \\
\text { Experts) }\end{array}$ & $\begin{array}{c}\text { Scenario 4 } \\
\text { (Compromise } \\
\text { Solution) }\end{array}$ & $\%$ \\
\hline C1 & 0.100 & 0.100 & 0.250 & 0.1500 & $15.00 \%$ \\
C2 & 0.100 & 0.100 & 0.250 & 0.1500 & $15.00 \%$ \\
C3 & 0.200 & 0.150 & 0.125 & 0.1583 & $15.83 \%$ \\
C4 & 0.200 & 0.150 & 0.125 & 0.1583 & $15.83 \%$ \\
C5 & 0.050 & 0.200 & 0.050 & 0.1000 & $10.00 \%$ \\
C6 & 0.050 & 0.050 & 0.025 & 0.0417 & $4.17 \%$ \\
C7 & 0.025 & 0.050 & 0.025 & 0.0333 & $3.33 \%$ \\
C8 & 0.050 & 0.050 & 0.025 & 0.0417 & $4.17 \%$ \\
C9 & 0.025 & 0.050 & 0.025 & 0.0333 & $3.33 \%$ \\
C10 & 0.200 & 0.100 & 0.100 & 0.1333 & $13.33 \%$ \\
$\Sigma$ & 1.000 & 1.000 & 1.000 & 1.0000 & $100 \%$ \\
\hline
\end{tabular}

\subsection{Creating a GIS Cloud Database}

The next step in the implementation of the DSC was the creation of a GIS Cloud database. The establishment of the database and data collecting was based on previously defined goals and the adopted GHS. This step is quite important because it also represents the creation of alternatives, which will later be used in the PROMETHEE method.

In order to collect all the necessary data, a data collection form was first created via the GIS Cloud website. The form is made in such a way that by filling it out, the data necessary for the evaluation of the criteria are obtained. More specifically, the form consisted of ten fields, which referred to ten criteria, which had to be fulfilled for each alternative. Figure 4 shows the creation of the data collection form on the GIS Cloud website. 


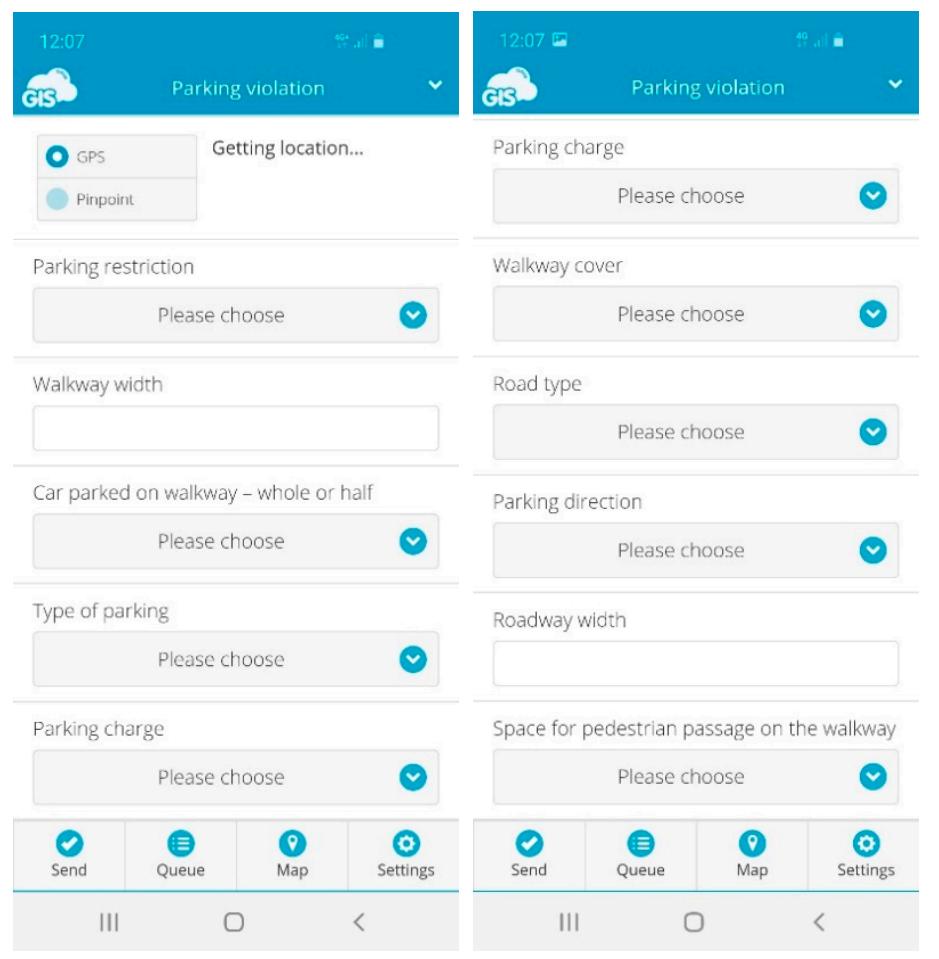

Figure 4. Data collecting form in application Mobile Data Collection.

The created form was then used in the GIS Cloud smartphone application "Mobile Data Collection", through which the data were obtained. Different datasets were collected in the period from 2016 to 2018 , but in order to validate the proposed DSC, the representative sample of a one-day time period was used. The chosen dataset consisted of a total of 462 illegally parked vehicles: 31 improperly parked vehicles were recorded in Bruna Bušića Street, 71 in Grge Novaka Street, 94 in Miroslava Krleže Street, 3 in Vjekoslava Paraća Street, 80 in Sućidar Street, 113 in Velebitska Street and 70 were recorded in Vukovarska Street. Each illegally parked vehicle, for which data were collected, represents one alternative, so this procedure actually provided 462 alternatives for further evaluation and ranking.

The application enables real-time data collecting and provides user-friendly, easy to learn tools. It is possible to choose between point, line or polygon project to collect different geometries in the field as well as to enrich data with multimedia. In the case of this study, a point data type was used to record the location of illegally parked vehicles. In addition to determining the data location with GPS, the application also allows using a pinpoint tool to add points manually. There is also an option of connecting an external GPS to achieve higher precision [5].

\subsection{Definition of the Decision Matrix and Priority Ranking of the Alternatives}

Once data on alternatives were collected, a decision matrix could be defined. The decision matrix contains the evaluation results of all alternatives according to all criteria-rows represent different alternatives, while each column represents a different criterion. Due to the large number of alternatives (462), only part of the decision matrix is contained in Table 4 corresponding to the first and the last 15 alternatives. Alternatives are in the table marked with labels regarding the streets where improperly parked vehicles were recorded, so BB represents Bruna Bušića Street, GN is Grge Novaka Street, MK is Miroslava Krleže Street, PA is Vjekoslava Paraća Street, SU is Sućidar Street, VEL is Velebitska Street and VUK stands for Vukovarska Street. The label of each alternative consists of the label of the street and the ordinal number of the vehicle recorded in that street. 
Table 4. Part of the decision matrix.

\begin{tabular}{|c|c|c|c|c|c|c|c|c|c|c|}
\hline \multirow{2}{*}{ Alternative Label } & \multicolumn{9}{|c|}{ Criteria Label } & \multirow[b]{2}{*}{ C10 } \\
\hline & $\mathrm{C} 1$ & $\mathrm{C} 2$ & $\mathrm{C} 3$ & C4 & $\mathrm{C} 5$ & C6 & $\mathrm{C7}$ & $\mathrm{C} 8$ & C9 & \\
\hline PA_1 & 0 & 0 & 1 & 1 & 2 & 0 & 1 & 1 & 7 & 1 \\
\hline PA_2 & 0 & 0 & 0 & 1 & 2 & 0 & 1 & 1 & 7 & 1 \\
\hline PA_3 & 0 & 0 & 0 & 1 & 2 & 0 & 1 & 1 & 7 & 1 \\
\hline MK_1 & 0 & 0 & 0 & 1 & 2 & 0 & 1 & 1 & 6 & 1 \\
\hline VEL_1 & 0 & 0 & 1 & 1 & 4.5 & 0 & 1 & 1 & 13.5 & 1 \\
\hline VEL_2 & 1 & 0 & 1 & 3 & 4.5 & 0 & 1 & 0 & 13.5 & 0 \\
\hline VEL_3 & 1 & 0 & 1 & 3 & 4.5 & 0 & 1 & 0 & 13.5 & 0 \\
\hline VEL_4 & 1 & 0 & 1 & 3 & 4.5 & 0 & 1 & 0 & 13.5 & 0 \\
\hline VEL_5 & 1 & 0 & 1 & 1 & 3 & 0 & 1 & 1 & 13.5 & 1 \\
\hline VEL_6 & 1 & 0 & 1 & 1 & 3 & 0 & 1 & 1 & 13.5 & 1 \\
\hline VEL_7 & 1 & 0 & 1 & 1 & 3 & 0 & 1 & 0 & 13.5 & 1 \\
\hline VEL_8 & 1 & 0 & 1 & 1 & 3 & 0 & 1 & 0 & 13.5 & 1 \\
\hline VEL_9 & 1 & 0 & 1 & 1 & 3 & 0 & 1 & 0 & 13.5 & 1 \\
\hline VEL_10 & 1 & 0 & 1 & 1 & 3 & 0 & 1 & 0 & 13.5 & 1 \\
\hline VEL_11 & 1 & 0 & 1 & 1 & 3 & 0 & 1 & 0 & 13.5 & 1 \\
\hline VEL_106 & 1 & 0 & 1 & 3 & 4.5 & 0 & 1 & 0 & 13.5 & 0 \\
\hline VEL_107 & 1 & 0 & 1 & 3 & 3 & 0 & 1 & 0 & 13.5 & 0 \\
\hline VEL_108 & 1 & 0 & 1 & 3 & 3 & 0 & 1 & 0 & 13.5 & 0 \\
\hline VEL_109 & 1 & 0 & 1 & 3 & 3 & 0 & 1 & 0 & 13.5 & 0 \\
\hline VEL_110 & 1 & 0 & 1 & 1 & 3 & 0 & 1 & 0 & 13.5 & 0 \\
\hline VEL_111 & 1 & 0 & 1 & 1 & 3 & 0 & 1 & 0 & 15 & 1 \\
\hline VEL_112 & 1 & 0 & 1 & 1 & 3 & 0 & 1 & 0 & 15 & 1 \\
\hline VEL_113 & 1 & 0 & 1 & 1 & 3 & 0 & 1 & 0 & 12 & 1 \\
\hline VUK_68 & 0 & 0 & 1 & 3 & 3 & 1 & 1 & 1 & 12 & 1 \\
\hline VUK_69 & 0 & 0 & 1 & 3 & 3 & 1 & 1 & 1 & 12 & 1 \\
\hline VUK_70 & 0 & 0 & 1 & 3 & 3 & 1 & 1 & 1 & 12 & 1 \\
\hline MK_89 & 0 & 0 & 1 & 4 & 6 & 0 & 1 & 0 & 9 & 1 \\
\hline MK_90 & 0 & 0 & 1 & 4 & 6 & 0 & 1 & 0 & 9 & 1 \\
\hline MK_91 & 0 & 0 & 1 & 4 & 6 & 0 & 1 & 0 & 9 & 1 \\
\hline MK_92 & 0 & 0 & 1 & 4 & 6 & 0 & 1 & 0 & 9 & 1 \\
\hline
\end{tabular}

Data processing and comparison were performed with the aid of the software Visual PROMETHEE [27], while the decision matrix, along with previously defined weights and preference functions, was the input for the comparison procedure. For the evaluation and comparison of alternatives, the multicriteria method PROMETHEE II was applied, which gives a complete ranking of the actions. Ranking is provided by the mutual comparison of all alternatives by all criteria according to stakeholders' opinions expressed through given criteria weights and selected preferences' functions. Given that there were 462 alternatives in the analysis, which would be too much to show in the article, Table 5 shows the complete ranking list with the phi net flow $(\phi)$ for the compromise solution for the first and the last 15 actions. 
Table 5. Net flow results—complete ranking (PROMETHEE II method) of the first and the last 15 actions by the compromise (fourth) scenario.

\begin{tabular}{|c|c|c|c|c|}
\hline Rank & Alternative Label & Phi & Phi(+) & Phi(-) \\
\hline 1 & VEL_107 & 0.2837 & 0.3763 & 0.0926 \\
\hline 1 & VEL_108 & 0.2837 & 0.3763 & 0.0926 \\
\hline 1 & VEL_109 & 0.2837 & 0.3763 & 0.0926 \\
\hline 4 & SU_80 & 0.2702 & 0.3829 & 0.1127 \\
\hline 5 & SU_77 & 0.2441 & 0.3575 & 0.1134 \\
\hline 5 & SU_79 & 0.2441 & 0.3575 & 0.1134 \\
\hline 7 & SU_78 & 0.2297 & 0.3568 & 0.1272 \\
\hline 8 & SU_66 & 0.2261 & 0.3464 & 0.1203 \\
\hline 8 & SU_69 & 0.2261 & 0.3464 & 0.1203 \\
\hline 8 & SU_70 & 0.2261 & 0.3464 & 0.1203 \\
\hline 11 & VEL_2 & 0.2232 & 0.3625 & 0.1394 \\
\hline 11 & VEL_3 & 0.2232 & 0.3625 & 0.1394 \\
\hline 11 & VEL_4 & 0.2232 & 0.3625 & 0.1394 \\
\hline 11 & VEL_102 & 0.2232 & 0.3625 & 0.1394 \\
\hline 11 & VEL_103 & 0.2232 & 0.3625 & 0.1394 \\
\hline $\begin{array}{c}\cdots \\
445\end{array}$ & SU_28 & -0.2403 & 0.0761 & 0.3164 \\
\hline 445 & SU_29 & -0.2403 & 0.0761 & 0.3164 \\
\hline 445 & SU_30 & -0.2403 & 0.0761 & 0.3164 \\
\hline 445 & SU_31 & -0.2403 & 0.0761 & 0.3164 \\
\hline 445 & SU_32 & -0.2403 & 0.0761 & 0.3164 \\
\hline 445 & SU_33 & -0.2403 & 0.0761 & 0.3164 \\
\hline 445 & SU_34 & -0.2403 & 0.0761 & 0.3164 \\
\hline 445 & SU_35 & -0.2403 & 0.0761 & 0.3164 \\
\hline 445 & SU_36 & -0.2403 & 0.0761 & 0.3164 \\
\hline 445 & SU_37 & -0.2403 & 0.0761 & 0.3164 \\
\hline 445 & SU_38 & -0.2403 & 0.0761 & 0.3164 \\
\hline 445 & SU_39 & -0.2403 & 0.0761 & 0.3164 \\
\hline 445 & SU_40 & -0.2403 & 0.0761 & 0.3164 \\
\hline 461 & MK_61 & -0.2578 & 0.0625 & 0.3204 \\
\hline 462 & VEL_70 & -0.3219 & 0.0307 & 0.3525 \\
\hline
\end{tabular}

The positive and negative phi net values shown in Table 5 were obtained by the PROMETHEE I method, which gives a partial ranking of the alternatives. The highest positive phi value has an alternative (i.e., improperly parked vehicle) labeled with SU_80, and the lowest value has a vehicle marked with VEL_70. The highest phi (-) value has a vehicle labeled as VEL_70, and the lowest phi (-) alternatives are VEL_107, VEL_108 and VEL_109.

Based on the positive and negative phi values, the final phi net flow was determined which shows preferences among alternative locations and provides a complete ranking. A higher phi net flow value gives a higher ranking and indicates a vehicle that, in the opinion of stakeholders, disrupts traffic and endangers its participants more with regard to the place and manner in which it is parked, and therefore should receive a higher penalty for improper parking. Vehicles with the same phi net flow value, according to the criteria and weights determined by the stakeholders, equally interfere with traffic and therefore have the same rank in the ranking scale and should pay the same amount of penalty. Three alternatives, VEL_107, VEL_108 and VEL_109, have the same highest phi net flow value, while the lowest value is for the vehicle labeled VEL_70.

Weight stability intervals, which are presented in Table 6, were calculated to obtain intervals of criteria weights in percentage, within which the final ranking of alternatives stays unchanged. The results of the calculation for Scenario 1, Scenario 2 and Scenario 3 show that the stability of the final order is very sensitive to changes in weights, i.e., that even a small change in weights will affect the final order. As expected, slightly higher stability intervals were obtained for Scenario 4 which is a compromise scenario (with weights obtained as arithmetic means). 
Table 6. Weight stability intervals.

\begin{tabular}{ccccc}
\hline \multicolumn{5}{c}{ Weight Stability Intervals [\%, \%] } \\
\hline Scenario 1 & $\begin{array}{c}\text { Scenario 2 } \\
{[\%, \%]}\end{array}$ & $\begin{array}{c}\text { Scenario } 3 \\
{[\%, \%]}\end{array}$ & $\begin{array}{c}\text { Scenario 4 } \\
{[\%, \%]}\end{array}$ \\
\hline C1 & {$[10.00 \%, 10.00 \%]$} & {$[10.00 \%, 10.00 \%]$} & {$[24.67 \%, 25.00 \%]$} & {$[14.99 \%, 15.03 \%]$} \\
\hline C2 & {$[9.86 \%, 10.56 \%]$} & {$[9.14 \%, 10.11 \%]$} & {$[24.99 \%, 25.67 \%]$} & {$[14.77 \%, 15.41 \%]$} \\
\hline C3 & {$[20.00 \%, 20.00 \%]$} & {$[15.00 \%, 15.00 \%]$} & {$[12.49 \%, 12.50 \%]$} & {$[15.80 \%, 15.84 \%]$} \\
\hline C4 & {$[19.99 \%, 20.15 \%]$} & {$[15.00 \%, 15.00 \%]$} & {$[12.49 \%, 12.51 \%]$} & {$[15.78 \%, 15.84 \%]$} \\
\hline C5 & {$[4.80 \%, 5.00 \%]$} & {$[20.00 \%, 20.00 \%]$} & {$[4.99 \%, 5.02 \%]$} & {$[10.00 \%, 10.03 \%]$} \\
\hline C6 & {$[5.00 \%, 5.00 \%]$} & {$[5.00 \%, 5.00 \%]$} & {$[2.50 \%, 2.51 \%]$} & {$[4.17 \%, 4.22 \%]$} \\
\hline C7 & {$[2.33 \%, 2.82 \%]$} & {$[5.00 \%, 5.15 \%]$} & {$[2.49 \%, 2.55 \%]$} & {$[3.26 \%, 3.45 \%]$} \\
\hline C8 & {$[5.00 \%, 5.00 \%]$} & {$[5.00 \%, 5.00 \%]$} & {$[2.50 \%, 2.50 \%]$} & {$[4.16 \%, 4.17 \%]$} \\
\hline C9 & {$[2.34 \%, 2.51 \%]$} & {$[4.99 \%, 5.00 \%]$} & {$[2.40 \%, 2.51 \%]$} & {$[3.32 \%, 3.34 \%]$} \\
\hline C10 & {$[20.00 \%, 20.01 \%]$} & {$[10.00 \%, 10.04 \%]$} & {$[10.00 \%, 10.04 \%]$} & {$[13.30 \%, 13.34 \%]$} \\
\hline
\end{tabular}

\subsection{Introduction of Investor Constraints}

After determining the phi net value and defining the full rank of alternatives, investor restrictions were introduced. Constraints were defined as the number of facilities that were planned to be built which included a total of five facilities-more precisely, four parking and one garage. This was the result of an agreement made by the city of Split representatives and traffic expert representatives. Taking into account the given constraints and estimated amount of money needed for the construction work of the planned facilities, a four-year financial plan was defined. According to the plan shown in Table 7, in the first year of implementing the project, EUR 130,000 would have to be collected to build the first parking area; in the second year, EUR 870,000 would need to be raised to build a garage; in the third year, EUR 187,000 would have to be collected to build two parking areas; and in the last year of implementing the project, EUR 173,000 would have to be collected to build a parking area.

Table 7. A four-year financial plan.

\begin{tabular}{ccc}
\hline Year & Construction Planned & Value (EUR) \\
\hline 1. & 1 parking area & 130,000 \\
2. & 1 garage & 870,000 \\
3. & 2 parking areas & 187,000 \\
4. & 1 parking area & 173,000 \\
\hline Total & 4 parking areas + 1 garage & $1,360,000$ \\
\hline
\end{tabular}

The money needed for these investments should be raised through charging the daily penalties $(D P)$ for improperly parked cars according to the proposed formula:

$$
D P_{i}=\frac{(T A M-Y * 365 * n) *\left(\phi_{i}-\phi_{n}\right)}{Y * 365 * \sum_{i=1}^{n}\left(\phi_{i}-\phi_{n}\right)}+1
$$

where TAM stands for the total amount of money, $Y$ is the number of years during which the money will be collected, $n$ is the total number of illegally parked cars and $\phi_{i}$ is the net flow of a car for which the penalty is being calculated. The formula was obtained in such a way that the share of each alternative in the total amount of penalties was determined with respect to its net flow, whereby each net flow was increased by the negative net flow value of the last ranked alternative to obtain positive values. From the total amount of funds to be collected, an amount equal to the product of the number of alternatives and the total number of days for collecting fines is deducted, which is distributed during 
the final determination of fines, thus ensuring that the minimum penalty is equal to 1 monetary unit of the currency in which it is expressed (in this case euro).

Table 8 shows daily penalties $(D P)$ calculated for the first and the last 15 actions (illegally parked cars) in the rank list.

Table 8. Daily penalties for the first and the last 15 ranked cars.

\begin{tabular}{cc}
\hline Alternative Label & Daily Penalty (EUR) \\
\hline VEL_107 & 2.91 \\
VEL_108 & 2.91 \\
VEL_109 & 2.91 \\
SU_80 & 2.87 \\
SU_77 & 2.79 \\
SU_79 & 2.79 \\
SU_78 & 2.74 \\
SU_66 & 2.73 \\
SU_69 & 2.73 \\
SU_70 & 2.73 \\
VEL_2 & 2.72 \\
VEL_3 & 2.72 \\
VEL_4 & 2.72 \\
VEL_102 & 2.72 \\
VEL_103 & 2.72 \\
. & \\
SU_28 & 1.26 \\
SU_29 & 1.26 \\
SU_30 & 1.26 \\
SU_31 & 1.26 \\
SU_32 & 1.26 \\
SU_33 & 1.26 \\
SU_34 & 1.26 \\
SU_35 & 1.26 \\
SU_36 & 1.26 \\
SU_37 & 1.26 \\
SU_38 & 1.26 \\
SU_39 & 1.26 \\
SU_40 & 1.26 \\
MK_61 & 1.20 \\
VEL_70 & 1.00 \\
\hline &
\end{tabular}

\section{Conclusions}

The present study aims to develop a decision support concept (DSC) to address the problem of illegally parked vehicles on sidewalks, with the goal of enabling the sustainability of pedestrian flow quality along urban roads. This approach, based on multicriteria analysis and the logic of decision support systems, and with the introduction of GIS as a database, helps in increasing the quality of parking management systems.

In transportation management processes, multicriteria methods are mainly used in the infrastructure planning phase and different studies of their use can be found in various countries around the world (e.g., [6-8]). When it comes to parking/garage planning, PROMETHEE and AHP methods are most commonly used in location selection for these facilities (e.g., [9-12]). There are also some studies dealing with improving the parking management system mostly by improving the ways of detecting parking violation and charging fines (e.g., [14-17]). However, a review of the literature did not find research dealing with the problem of illegal parking in a similar way as this article deals with. Establishing the penalty system proposed by this approach is a unique solution as it allows raising a sufficient amount of money to build new parking facilities, thus increasing the number of parking spaces and permanently reducing the problem of parking violations. 
Validation of the proposed DSC was carried out in the city of Split in Croatia and included three groups of stakeholders and 462 alternatives or improperly parked vehicles. The AHP method was used to assign weights to the criteria, in which all stakeholders participated, and for the final analysis, a compromise scenario was selected, thus meeting the requirements of all stakeholder groups. The PROMTHEE II method was applied to obtain a complete ranking of the alternatives. This ranking was further used to calculate parking tickets, according to the proposed expression (6), in such a way that higher-ranked vehicles receive a higher penalties than lower-ranked ones. Three alternatives, VEL_107, VEL_108 and VEL_109, have the same highest phi net flow value $(\phi=0.2837)$, on the basis of which they were given a daily penalty of EUR 2.91, while the lowest phi net flow value $(\phi=-0.3219)$ is for the vehicle labeled VEL_70, with the daily penalty of EUR 1 . What can be noticed, and what is a great advantage of this model, is that the penalties are relatively small and therefore do not burden the driver's budget, but on the other hand, their implementation in this way can raise enough money to solve the problem permanently by building new facilities.

The proposed DSC is unique and easy to use; in addition, it is adoptable, and with minor changes, it can be applied to different areas where there are similar problems with parking violation and lack of legal parking spaces. It involves the active participation of stakeholders with respect to their opinions and requests and provides a compromise solution that meets everyone's demands in the best possible way. In this way, the problem was viewed systematically, taking into account all of its characteristics that the stakeholders considered important through criteria. A possible limitation of this system may be the length of the procedure, the difficulty in finding stakeholders and the problem of their agreement, since the establishment of the model requires their consensus and the approval of all stakeholder groups. In order not to prolong the process too much and to make it easier for the groups to find a common solution, it is important to choose an appropriate number of representatives for each group of stakeholders, which in this case proved to be three for each group. However, what is most important, and the greatest advantage of this model, is that raising funds by charging relatively low fines provides a permanent solution to the problem as it enables the construction of new parking facilities. This model has developed a measure to address the problem of illegal parking by collecting fines, which provides opportunities for future research in which the methodology could be adapted and expanded to include other measures to address this problem. Moreover, the research could be extended in the future to the methods of detecting illegally parked vehicles, which would provide a comprehensive system that would significantly contribute to and facilitate the management of traffic and traffic infrastructure.

Author Contributions: Conceptualization, M.I., J.K., K.R. and N.J.; methodology, M.I., J.K., K.R. and N.J.; software, M.I., J.K., K.R. I and N.J.; validation, M.I., J.K., K.R. and N.J.; formal analysis, M.I., J.K., K.R. and N.J.; investigation, M.I., J.K., K.R. and N.J.; resources, M.I., J.K., K.R. and N.J.; data curation, M.I., J.K., K.R. and N.J.; writing-original draft preparation, M.I., J.K., K.R. and N.J.; writing—review and editing, M.I., J.K., K.R. and N.J.; visualization, M.I., J.K., K.R. and N.J.; supervision, M.I., J.K., K.R. and N.J.; project administration, M.I., J.K., K.R. and N.J.; funding acquisition, M.I., J.K., K.R. and N.J. All authors have read and agreed to the published version of the manuscript.

Funding: This research received no external funding.

Acknowledgments: This research is partially supported through project KK.01.1.1.02.0027, a project co-financed by the Croatian Government and the European Union through the European Regional Development Fund-the Competitiveness and Cohesion Operational Programme.

Conflicts of Interest: The authors declare no conflict of interest.

\section{References}

1. Maletin, M. Planiranje i Projektovanje Saobraćajnica u Gradovima, 2nd ed.; Orion art: Belgrade, Serbia, 2009.

2. Kraljević, I. Funkcija Uličnog Parkiranja u Gradu Zagrebu. Master's Thesis, University of Zagreb, Faculty of Transport and Traffic Sciences, Zagreb, Croatia, 1 March 2016.

3. Brans, J.P.; Mareschal, B.; Vincke, P.H. PROMETHEE-A New Family of Outranking Methods in Multicriteria Analysis; Operational Research IFORS 84; Brans, J.P., Ed.; Universite Libre de Bruxelles: Amsterdam, The Netherlands, 1984; pp. 477-490.

4. Saaty, T.L. The Analytic Hierarchy Process; McGraw Hill. International: New York, NY, USA, 1980. 
5. GIS Cloud. About Us. Available online: https://www.giscloud.com/about-us/ (accessed on 15 September 2018).

6. Deluka-Tibljaš, A.; Karleuša, B.; Dragičević, N. Pregled primjene metoda višekriterijske analize pri donošenju odluka o prometnoj infrastrukturi. Građevinar 2013, 65, 619-631.

7. Jajac, N.; Marović, I.; Hanak, T. Decision Support to Management of Transportation Projects: Improvement of Urban Road Infrastructure Planning. Građevinar 2015, 67, 131-141.

8. Jajac, N.; Knezić, S.; Mladineo, N. DSS for urban infrastructure management: Parking garages case study. In Proceedings of the 8th International Conference on Organization, Technology and Management in Construction, Umag, Croatia, 17-20 September 2008; Radujković, M., Mlinarić, V., Eds.; Faculty of Civil Engineering, University of Zagreb: Zagreb, Croatia, 2008.

9. Jajac, N.; Marović, I.; Mladineo, M. Planning support concept to implementation of sustainable parking development projects in ancient Mediterranean cities. Croat. Oper. Res. Rev. 2014, 5, 345-359. [CrossRef]

10. Bonić, N.; Brkić, I.; Domljan, I. Odabir najpovoljnije lokacije parkirališta korištenjem višekriterijskog odlučivanja. Elektron. Zb. Rad. Građevinskog Fak. 2017, 7, 101-116.

11. Deluka-Tibljaš, A.; Karleuša, B.; Benac, Č. AHP methodology application in garage-parking facility location selection. Promet Traffic Transp. 2011, 23, 303-313. [CrossRef]

12. Jelokhani-Niaraki, M.; Malczewski, J. A group multicriteria spatial decision support system for parking site selection problem: A case study. Land Use Policy 2015, 42, 492-508. [CrossRef]

13. Jajac, N.; Marovic, I.; Baucic, M. Decision support concept for managing the maintenance of city parking facilities. e-GFOS 2014, 5, 60-69. [CrossRef]

14. Davtyan, R. Decision making analysis on parking meters. In Proceedings of the ASEE 2014 Zone I Conference, Bridgpeort, CT, USA, 3-5 April 2014.

15. Khantasak, S.; Jindapetch, N.; Hoyingcharoen, P.; Chetpattananondh, K.; Ikura, M.; Chumpol, S. Parking violation detection system based on video processing. In Proceedings of the 2018 IEEE 5th International Conference on Smart Instrumentation, Measurement and Application (ICSIMA), Songkla, Thailand, 28-30 November 2018; IEEE: New York, NY, USA, 2018; pp. 1-5.

16. Kim, A.R.; Rhee, S.Y.; Jang, H.W. Lane detection for parking violation assessments. Int. J. Fuzzy Log. Intell. Syst. 2016, 16, 13-20. [CrossRef]

17. Dinh, T.; Kim, Y. A novel location-centric IoT-cloud based on-street car parking violation management system in smart cities. Sensors 2016, 16, 810. [CrossRef] [PubMed]

18. Saaty, T.L. Analytic hierarchy process. In Encyclopedia of Biostatistics; Armitage, P., Colton, T., Eds.; John Wiley \& Sons, Ltd.: New York, NY, USA, 2005.

19. Cheng, E.W.L.; Li, H. Analytic hierarchy process: An approach to determine measures for business performance. Meas. Bus. Excell. 2001, 3, 30-36. [CrossRef]

20. Brans, J.P.; Mareschal, B. PROMETHEE: MCDM problems with segmetation constraints. INFOR 1992, 30, 85-86. [CrossRef]

21. Macharis, C.; Springael, J.; De Brucker, K.; Verbeke, A. PROMETHEE and AHP: The design of operational synergies in multicriteria analysis.: Strengthening PROMETHEE with ideas of AHP. Eur. J. Oper. Res. 2004, 153, 307-317. [CrossRef]

22. Triantaphyllou, E.; Mann, S.H. Using the Analytic Hierarchy Process for decision making in engineering applications: Some challenges. Int. J. Ind. Eng. Appl. Pract. 1995, 2, 35-44.

23. Bitunjac, I.; Jajac, N.; Katavić, I. Decision support to sustainable management of bottom trawl fleet. Sustainability 2016, 8, 204. [CrossRef]

24. Jajac, N.; Bilic, I.; Mladineo, M. Application of multicriteria methods to planning of investment projects in the field of civil engineering. Croat. Oper. Res. Rev. 2012, 3, 113-125.

25. Jajac, N.; Kilić, J.; Rogulj, K. An Integral Approach to Sustainable Decision-Making within Maritime Spatial Planning-A DSC for the Planning of Anchorages on the Island of Šolta, Croatia. Sustainability 2019, 11, 104. [CrossRef]

26. Urbos d.o.o. Split. Urbanistički Plan Uređenja Stambenog Naselja Vrh Sućidra. Available online: www.split. hr/lgs.axd?t=16\&id=5051 (accessed on 20 September 2018). 
27. Mareschal, B. Visual PROMETHEE. 2011. Available online: http://www.promethee-gaia.net/visualpromethee. html (accessed on 15 March 2020).

28. Jajac, N.; Bilić, I.; Ajduk, A. Decision support concept to management of construction projects-problem of construction site selection. Croat. Oper. Res. Rev. 2013, 4, 235-246.

Publisher's Note: MDPI stays neutral with regard to jurisdictional claims in published maps and institutional affiliations.

(C) 2020 by the authors. Licensee MDPI, Basel, Switzerland. This article is an open access article distributed under the terms and conditions of the Creative Commons Attribution (CC BY) license (http://creativecommons.org/licenses/by/4.0/). 